\title{
Screening for Anal Dysplasia in HIV-Infected Men Who Have Sex with Men by Anal Cytology, Human Papillomavirus Testing and Anoscopy
}

\author{
Eefje Jong ${ }^{1,2^{*}}$, Jan Willem Mulder ${ }^{2}$, Anne Catherina Theresia Maria Depla ${ }^{3}$, \\ Eric Cornelis Maria van Gorp ${ }^{4}$, Johan Westerga ${ }^{5}$, Claudie Flohil ${ }^{5}$, Anja Johanna Heijne-Tol ${ }^{6}$, \\ Paulus Henricus Marinus Smits ${ }^{6}$
}

\begin{abstract}
${ }^{1}$ Themba Lethu Clinic, Helen Joseph Hospital, Johannesburg, South Africa; ${ }^{2}$ Department of Internal Medicine, Slotervaart Hospital, Amsterdam, the Netherlands; ${ }^{3}$ Department of Gastroenterology, Slotervaart Hospital, Amsterdam, the Netherlands; ${ }^{4}$ Department of Virology, Erasmus Medical Centre, Rotterdam, the Netherlands; ${ }^{5}$ Department of Pathology, Slotervaart Hospital, Amsterdam, the Netherlands; ${ }^{6}$ Department of Molecular Biology, Slotervaart Hospital, Amsterdam, the Netherlands.

Email: jong.eefje@gmail.com
\end{abstract}

Received April 2 ${ }^{\text {nd }}$, 2011; Revised April 25 ${ }^{\text {th }}$ 2011; Accepted May 25 ${ }^{\text {th }}, 2011$.

\begin{abstract}
The incidence of anal cancer in HIV-infected men who have sex with men (MSM) is increasing and screening is advocated. In a cross-sectional study anal cytology specimens from 58 HIV-infected MSM were analyzed for adequacy, cytology and HPV DNA testing results and compared to findings on anoscopy. The adequacy of cytology specimens was high. In 34 (63\%) of anal swab samples any grade of dysplasia was observed compared to 41 (71\%) of biopsy specimens. The cytology specimens revealed high-grade dysplasia in 4 (7\%) compared to 29 (50\%) of biopsy specimens. The prevalence of high-risk HPV types was $90 \%$ by using the SPF10 PCR and $81 \%$ by using the Hybrid Capture II assay. Because of the high HPV prevalence, HPV DNA testing alone is not a suitable diagnostic screening tool for detecting anogenital lesions in this specific MSM population. Screening should include both anal cytology and anoscopy.
\end{abstract}

Keywords: HIV, Men, Human Papillomavirus, Anal Cancer, Screening

\section{Introduction}

The incidence of anal cancer in HIV-infected and HIVnegative men who have sex with men (MSM) is increasing [1-3]. The occurrence of high-grade anal dysplasia and anal cancer is strongly associated with HIV infection, a history of receptive anal intercourse and anogenital human papillomavirus (HPV) infection [3-9].

Introduction of the cervical cancer screening program resulted in a decrease in cervical cancer incidence rates in Western countries from 45 per 100,000 person-years to 8 per 100,000 person-years [10]. It is because of this successful methodology that screening programmes for anal dysplasia are advocated. The hallmark of cervical cancer screening is the Pap smear, which enables cytological examination of exfoliated cells [11]. Patients with abnormal cervical cytology are referred for further evaluation with cervical colposcopy. However, sensitivity of cytology is not optimal. The sensitivity of atypical squamous cells of undetermined significance (ASCUS) cervical cy- tology can be greatly improved with the introduction of HPV DNA testing using the Hybrid Capture II (HCII) assay for the detection of high-risk HPV strains [12-15]. Although HCII testing is not yet FDA approved for use in the anal canal, it has been shown to improve the ability to predict high-grade dysplasia in MSM with ASCUS cytology. Referring only those with ASCUS and high-risk HPV genotypes for anoscopy prevents unnecessary diagnostic procedures in this group [16].

We investigated the prevalence of anal dysplasia in a group of HIV-infected MSM using clinician-collected anal cytology and HPV DNA testing compared to findings on anoscopy with biopsy. The adequacy of the different screening methods was determined. The findings of this study could be used to determine the best future screening strategy for anal dysplasia in HIV-infected MSM.

\section{Study Design}

A cross-sectional study was conducted at the HIV outpa- 
tient clinic of the Slotervaart Hospital, Amsterdam, the Netherlands. HIV-infected MSM were asked to participate. All patients provided written informed consent before inclusion in the study. Inclusion started in March 2008. Demographic and clinical information was collected by using a standardized questionnaire or was retrieved from the patient's medical file. In each patient who consented with anoscopy a clinician-collected anal swab was taken for cytological examination and HPV DNA testing. The study was approved by the Institutional Review Board.

\subsection{Anal Cytology}

The clinician-collected anal cytology sample was acquired through inserting a cytobrush $5 \mathrm{~cm}$ into the anal canal. The cytobrush was removed while rotating 360 degrees and pressing to the wall of the anal canal. The collected sample was fixed in $1.5 \mathrm{ml}$ of Surepath ${ }^{\circledR}$ preservative fluid (Becton Dickinson, USA) for liquid-based cytology and HPV testing. Preparations were produced analogous to thin layer liquid based cervical cytology using Autocyte (Autocyte, Tripath Imaging Inc, Burlington, USA).

\subsection{Anoscopy}

Anoscopy was done with the use of a conventional gynaecologic colposcope. All exams were performed by or under direct supervision of one single experienced gastroenterologist during the whole study period. At first a digital anorectal examination was performed. An anal cytology sample was collected as described in the previous paragraph. Thereafter a 3\% acetic acid solution was locally applied by inserting and rotating a soaked wooden cotton-tipped swab. A second swab with acetic acid was inserted and left in place for one minute. Next, the proctoscope was introduced to inspect the anal canal. The acetowhite areas and the areas with a suspicious appearance were biopsied. In case of no suspected area, no biopsies were taken.

\subsection{Biopsy and Anal Swab Sample Preparation}

All cytological and histological preparations and specimens were examined by two experienced pathologists. Cellular changes were determined using standard criteria for gynaecologic cytology in accordance with the Bethesda system [17]. Cytological specimens were classified as normal, ASCUS, low-grade squamous intraepithelial lesion (LSIL), or high-grade squamous intraepithelial lesion (HSIL). Histological specimens were classified as normal, anal intraepithelial neoplasia (AIN) grade 1, AIN grade 2 , AIN grade 3 , or squamous cell carcinoma (SCC).

\subsection{HPV DNA Testing}

After processing the anal swab sample for cytological examination the remainder of the sample was sent to the Molecular Biology Department for HPV DNA testing. All samples were stored at $5^{\circ} \mathrm{C}$ until further processing. After DNA isolation, HPV DNA was amplified by the SPF10 PCR primer set (Innogenetics, Gent, Belgium). Test characteristics and reaction conditions have been described

Before, [18] from 43 patients enough material was available to be analyzed on the presence of high risk HPV DNA using the HCII test (Qiagen, Hilden, Germany).

\section{Results}

The results of 58 HIV-infected MSM are presented here. The patient characteristics are shown in Table 1. The mean age was 44.8 years $( \pm 9.4)$, $85 \%$ was using combined antiretroviral therapy, $71 \%$ had a HIV viral load below 40 copies $/ \mathrm{ml}$, and $57 \%$ reported receptive anal intercourse in the last 6 months.

Table 2 outlines the results of the clinician-collected anal swab samples as compared to the findings on anoscopy. Specimen adequacy for cytological specimens was high (53/58, 91\%). In 34 (63\%) of anal swab samples any grade of dysplasia was observed compared to 41 (71\%) of biopsy specimens. The cytology specimens revealed high-grade dysplasia in 4 (7\%) participants compared to 29 (50\%) of biopsy specimens. The agreement between findings on cytology and histology was poor (kappa 0.20). No significant association between CD4 cell count, HIV viral load, receptive anal intercourse in the last 6 months, treatment for sexually transmitted diseases in the last year or smoking and any grade of anal dysplasia was observed.

The high-risk HPV prevalence in the cytology specimens was $90 \%$. All patients infected with HPV DNA harboured a median number of 2 (range 0 - 7) high-risk HPV types (data not shown). In the 43 samples that were analyzed with both the SPF10 PCR and the HCII assay identical test results for the presence or absence of high-risk HPV types were found in 35 patients (81\%).

\section{Discussion}

In the study presented here we evaluated different aspects of a screening programme for anal dysplasia in HIV-infected MSM. Cytological findings and HPV DNA testing results on clinician-collected cytology specimens were compared to histological findings.

The HPV prevalence in our study population was high and infections with multiple high-risk HPV types were 
Table 1. Baseline characteristics of HIV-infected MSM (n = 58).

\begin{tabular}{|c|c|}
\hline \multicolumn{2}{|l|}{ Characteristic } \\
\hline Mean age in years $( \pm$ SD) & $44.8( \pm 9.4)$ \\
\hline \multicolumn{2}{|l|}{ Ethnicity } \\
\hline Caucasian & $51(86 \%)$ \\
\hline Latino & $4(7 \%)$ \\
\hline Other & $4(7 \%)$ \\
\hline \multicolumn{2}{|l|}{ CD4 cell count (cells/mm3) } \\
\hline$<200$ & $1(2 \%)$ \\
\hline $200-500$ & $25(42 \%)$ \\
\hline$>500$ & $33(56 \%)$ \\
\hline \multicolumn{2}{|l|}{ HIV viral load (copies/ml) } \\
\hline$<40$ & $42(71 \%)$ \\
\hline $40-100.000$ & $14(24 \%)$ \\
\hline$>100.000$ & $3(5 \%)$ \\
\hline Use of ART & $50(85 \%)$ \\
\hline \multicolumn{2}{|l|}{ Type of ART } \\
\hline NRTI + NNRTI & $36(72 \%)$ \\
\hline NRTI + PI & $8(16 \%)$ \\
\hline NRTI & $2(4 \%)$ \\
\hline Other & $4(8 \%)$ \\
\hline Duration of ART use (months, IQR) & $106(24-137)$ \\
\hline Receptive anal intercourse in last 6 months & $57 \%$ \\
\hline \multicolumn{2}{|c|}{ Frequency of receptive anal intercourse in last 6 months } \\
\hline 0 & $43 \%$ \\
\hline $1-5$ & $36 \%$ \\
\hline $6-20$ & $18 \%$ \\
\hline $21-40$ & $3 \%$ \\
\hline Number of sex partners in last 6 months & $19 \%$ \\
\hline 0 & $34 \%$ \\
\hline 1 & $24 \%$ \\
\hline $2-10$ & $12 \%$ \\
\hline $11-20$ & $7 \%$ \\
\hline $21-30$ & $4 \%$ \\
\hline \multicolumn{2}{|l|}{$>30$} \\
\hline \multicolumn{2}{|c|}{ Received treatment for sexually transmitted disease in last year } \\
\hline Gonorrhoea & $11 \%$ \\
\hline Chlamydia & $11 \%$ \\
\hline Syphillis & $18 \%$ \\
\hline Current smoker & $39 \%$ \\
\hline
\end{tabular}

common. The high HPV prevalence and detection of multiple HPV genotypes is in accordance with previous studies in HIV-infected MSM [19-23]. Due to the very high HPV prevalence found with both the SPF10 PCR and HCII assay as HPV DNA testing methods, HPV DNA testing lacks specificity to detect anal dysplasia in this specific patient population.

A high prevalence of any grade of dysplasia was observed in both cytology and histology specimens. No data on sensitivity and specificity were calculated be- cause biopsies were not done in every patient and the patient number is too low to perform any statistical analysis on. The observed agreement between findings on cytology and histology was poor. Cytological testing was complicated by a generally low cell yield. Furthermore, inadequate sampling of the transformation zone due to blind sampling could lead to an incorrect classification of dysplasia on cytology. This is also reflected in the high proportion of ASCUS cytology. In $44 \%$ of clinician-collected cytological samples ASCUS was reported. 
Table 2. Comparison of findings for clinician-collected anal cytology specimens with biopsy specimens $(\mathrm{n}=58)$.

\begin{tabular}{ccccccccc}
\hline & Histology & & & & & \\
\hline Cytology & No biopsy & Normal & AIN1 & AIN2 & AIN3 & SCC & Ulcer & Total \\
Inadequate & 0 & 1 & 1 & 1 & 0 & 0 & 0 & 3 \\
Normal & 5 & 4 & 3 & 8 & 1 & 0 & 0 & 21 \\
ASCUS & 4 & 1 & 6 & 6 & 8 & 0 & 1 & 26 \\
LSIL & 1 & 0 & 1 & 1 & 1 & 0 & 0 & 4 \\
HSIL & 0 & 1 & 0 & 2 & 0 & 1 & 0 & 4 \\
Total & 1 & 7 & 11 & 18 & 10 & 1 & 1 & 58 \\
\hline
\end{tabular}

AIN, anal intraepithelial neoplasia grade 1; AIN2, anal intraepithelial neoplasia grade 2; AIN3, anal intraepithelial neoplasia grade 3; SCC, squamous cell carcinoma; ASCUS, atypical squamous cells of undetermined significance; LSIL, low-grade intraepithelial lesion, HSIL, high-grade intraepithelial lesion.

Other studies showed incidence rates of ASCUS cytology in the anal canal of $14 \%-78 \%$ in HIV-infected MSM. These studies indicated that the incidence of ASCUS cytology in the anal canal is higher than in the cervix [16, 23,24]. Adding the HCII assay in case of ASCUS cytology, as is currently done for ASCUS on cervical cytology, could improve the clinical sensitivity to detect anal dysplasia [25-27]. However, in this study the HPV prevalence when using the HCII assay was still $81 \%$ so adding this assay would not improve clinical sensitivity. In two large studies on anal cancer screening in HIV-infected patients, in a predominantly male HIVinfected population, anal cytology and HPV DNA detection have high sensitivity but low specificity for detecting high-grade anal dysplasia [23,28].

In the study presented here patients with high-grade dysplasia were referred for treatment to a surgeon with experience in the field of anal surgery. If patients refused referral for treatment a follow-up anoscopy was scheduled in a year. All patients without a treatment indication were scheduled to repeat anal cytology and HPV testing in two years followed by anoscopy. A more strict screening algorithm was suggested by Goldstone et al. [29]. The guidelines from the European AIDS Clinical Society (EACS) recommend a digital rectal exam with or without Pap smear testing with a screening interval of 1 3 years [30].

The considerable prevalence of high-grade dysplasia on anoscopy with biopsy calls for a routine screening program for anal dysplasia in HIV-infected MSM. However, the optimal screening strategy to limit the amount of patients requiring anoscopy needs to be determined still. Testing for HPV DNA using the HCII assay lacked clinical sensitivity as over $80 \%$ of participants were HPV-infected. Self-collected anal cytology could be a promising sampling method, but the availability of anoscopy and trained physicians is a prerequisite in the implementation of a screening program on anal dysplasia, because as it currently stands almost all patient require anoscopy. In agreement with our results, a study has been done assessing cost-effectiveness of high-resolution anoscopy (HRA), anal cytology, and anal HPV detection in screening for AIN2/3 in HIV-positive MSM. The direct use of HRA is the most cost-effective strategy for detecting AIN2/3 in HIV-infected MSM [31].

In conclusion, the prevalence of anal HPV infection and anal dysplasia on cytological and histological samples in HIV-infected MSM is high. The agreement between cytology and histology results is poor. Given the high HPV prevalence HPV DNA testing should not be routinely applied in this specific patient population of MSM. Screening should include anoscopy. Finally, follow-up is essential to improve our knowledge on the natural course of anal dysplasia and to determine the optimal screening interval.

\section{Acknowledgements}

We would like to thank Mrs. H. Paap, Mrs. M. Stroomer and Mr. D.J. Vlasblom, HIV nurse consultants, for their great help with including patients and their logistical support. Many thanks to Ms. C. Wientjes, MD, Ms. S. Willemse, MD, and Mr. P. Smit, MD, for their practical support with anoscopy.

\section{REFERENCES}

[1] M. S. Shiels, R. M. Pfeiffer, M. H. Gail, H. I. Hall, J. Li, A. K. Chaturvedi, K. Bhatia, T. S. Uldrick, R. Yarchoan, J. J. Goedert and E. A. Engels, "Cancer Burden in the HIV-Infected Population in the United States," Journal of the National Cancer Institute, Vol. 103, No. 9, 2011, pp. 753-762. doi:10.1093/jnci/djr076

[2] P. V. Chin-Hong, E. Vittinghoff, R. D. Cranston, L. Browne, S. Buchbinder, G. Colfax, C. M. Da, T. Darragh, D. J. Benet, F. Judson, B. Koblin, K. H. Mayer and J. M. Palefsky, "Age-Related Prevalence of Anal Cancer Precursors in Homosexual Men: The EXPLORE Study," Journal of the National Cancer Institute, Vol. 97, No. 12, 2005, pp. 896-905. doi:10.1093/jnci/dji163

[3] J. M. Palefsky, E. A. Holly, J. T. Efirdc, C. M. Da, N. Jay, J. M. Berry and T. M. Darragh, “Anal Intraepithelial Neoplasia in the Highly Active Antiretroviral Therapy Era among HIV-Positive Men Who Have Sex with Men,” 
AIDS, Vol. 19, No. 3, 2005, pp. 1407-1414. doi:10.1097/01.aids.0000181012.62385.4a

[4] J. M. Palefsky, E. A. Holly, M. L. Ralston, S. P. Arthur, N. Jay, J. M. Berry, M. M. DaCosta, R. Botts and T. M. Darragh, "Anal Squamous Intraepithelial Lesions in HIV-Positive and HIV-Negative Homosexual and Bisexual Men: Prevalence and Risk Factors," Journal of Acquired Immune Deficiency Syndromes \& Human Retrovirology, Vol. 17, No. 4, 1998, pp. 320-326. doi:10.1097/00042560-199804010-00005

[5] J. M. Palefsky, E. A. Holly, M. L. Ralston, N. Jay, J. M. Berry and T. M. Darragh, "High Incidence of Anal High-Grade Squamous Intra-Epithelial Lesions among HIV-Positive and HIV-Negative Homosexual and Bisexual Men,” AIDS, Vol. 12, No. 5, 1998, pp. 495-503. doi:10.1097/00002030-199805000-00011

[6] A. de Pokomandy, D. Rouleau, G. Ghattas, H. Trottier, S. Vezina, P. Cote, J. Macleod, G. Allaire, R. Hadjeres, E. L. Franco and F. Coutlee, "HAART and Progression to High-Grade Anal Intraepithelial Neoplasia in Men Who Have Sex with Men and Are Infected with HIV," Clinical Infectious Diseases, Vol. 52, No. 9, 2011, pp. 1174-1181. doi:10.1093/cid/cir064

[7] I. E. Salit, J. Tinmouth, S. Chong, J. Raboud, C. Diong, D. Su, M. Sano, A. Lytwyn, W. Chapman and J. Mahony, "Screening for HIV-Associated Anal Cancer: Correlation of HPV Genotypes, P16, and E6 Transcripts with Anal Pathology," Cancer Epidemiology, Biomarkers \& Prevention, Vol. 18, No. 7, 2009, pp. 1986-1992. doi:10.1158/1055-9965.EPI-08-1141

[8] T. J. Wilkin, S. Palmer, K. F. Brudney, M. A. Chiasson and T. C. Wright, "Anal Intraepithelial Neoplasia in Heterosexual and Homosexual HIV-Positive Men with Access to Antiretroviral Therapy," Journal of Infectious Diseases, Vol. 190, No. 9, 2004, pp. 1685-1691. doi:10.1086/424599

[9] J. R. Daling, M. M. Madeleine, L. G. Johnson, S. M. Schwartz, K. A. Shera, M. A. Wurscher, J. J. Carter, P. L. Porter, D. A. Galloway and J. K. McDougall, "Human Papillomavirus, Smoking, and Sexual Practices in the Etiology of Anal Cancer," Cancer, Vol. 101, No. 2, 2004, pp. 270-280. doi:10.1002/cncr.20365

[10] J. R. Qualters, N. C. Lee, R. A. Smith and R. E. Aubert, "Breast and Cervical Cancer Surveillance, United States, 1973-1987," Morbidity and Mortality Weekly Report CDC Surveill Summ, Vol. 41, No. 2, 1992, pp. 1-7.

[11] D. Solomon, D. Davey, R. Kurman, A. Moriarty, D. O'Connor, M. Prey, S. Raab, M. Sherman, D. Wilbur, T. Wright Jr. and N. Young, "The 2001 Bethesda System: Terminology for Reporting Results of Cervical Cytology," Journal of the American Medical Association, Vol. 287, No. 16, 2002, pp. 2114-2119. doi:10.1001/jama.287.16.2114

[12] J. Monsonego, G. Pollini, M. J. Evrard, P. Sednaoui, L. Monfort, D. Quinzat, R. Dachez and K. Syrjanen, "Linear Array Genotyping and Hybrid Capture II Assay in Detecting Human Papillomavirus Genotypes in Women Re- ferred for Colposcopy Due to Abnormal Papanicolaou Smear," International Journal of STD \& AIDS, Vol. 19, No. 6, 2008, pp. 385-392.

[13] C. Baleriola, D. Millar, J. Melki, N. Coulston, P. Altman, N. Rismanto and W. Rawlinson, "Comparison of a Novel HPV Test with the Hybrid Capture II (hcII) and a Reference PCR Method Shows High Specificity and Positive Predictive Value for 13 High-Risk Human Papillomavirus Infections,” Journal of Clinical Virology, Vol. 42, No. 1, 2008, pp. 22-26. doi:10.1016/j.jcv.2007.12.008

[14] S. L. Huang, A. Chao, S. Hsueh, F. Y. Chao, C. C. Huang, J. E. Yang, C. Y. Lin, C. C. Yan, H. H. Chou, K. G. Huang, H. J. Huang, T. I. Wu, M. J. Tseng, J. T. Qiu, C. T. Lin, T. C. Chang and C. H. Lai, "Comparison between the Hybrid Capture II Test and an SPF1/GP6+ PCRBased Assay for Detection of Human Papillomavirus DNA in Cervical Swab Samples,” Journal of Clinical Microbiology, Vol. 44, No. 5, 2006, pp. 1733-1739. doi:10.1128/JCM.44.5.1733-1739.2006

[15] L. Z. Mo, S. Monnier-Benoit, B. Kantelip, A. Petitjean, D. Riethmuller, J. L. Pretet and C. Mougin, "Comparison of AMPLICOR and Hybrid Capture II Assays for High Risk HPV Detection in Normal and Abnormal Liquid-Based Cytology: Use of INNO-LiPA Genotyping Assay to Screen the Discordant Results," Journal of Clinical Virology, Vol. 41, No. 2, 2008, pp. 104-110. doi:10.1016/j.jcv.2007.09.012

[16] S. E. Goldstone, A. Z. Kawalek, R. N. Goldstone and A. B. Goldstone, "Hybrid Capture II Detection of Oncogenic Human Papillomavirus: A Useful Tool When Evaluating Men Who Have Sex with Men with Atypical Squamous Cells of Undetermined Significance on Anal Cytology,” Diseases of the Colon \& Rectum, Vol. 51, No. 7, 2008, pp. 1130-1136. doi:10.1007/s10350-008-9306-4

[17] K. Holcomb and C. D. Runowicz, "Cervical Cancer Screening," Surgical Oncology Clinics of North America, Vol. 14, No. 14, 2005, pp. 777-797. doi:10.1016/j.soc.2005.05.011

[18] B. Kleter, L. J. van Doorn, S. J. ter, L. Schrauwen, K. K. van, M. Burger, H. B. ter and W. Quint, "Novel ShortFragment PCR Assay for Highly Sensitive Broad-Spectrum Detection of Anogenital Human Papillomaviruses," American Journal of Pathology, Vol. 153, No. 6, 1998, pp. 1731-1739. doi:10.1016/S0002-9440(10)65688-X

[19] J. M. Palefsky, E. A. Holly, M. L. Ralston and N. Jay, "Prevalence and Risk Factors for Human Papillomavirus Infection of the Anal Canal in Human Immunodeficiency Virus (HIV)-Positive and HIV-Negative Homosexual Men,” Journal of Infectious Diseases, Vol. 177, No. 2, 1998, pp. 361-367. doi:10.1086/514194

[20] A. de Pokomandy, D. Rouleau, G. Ghattas, S. Vezina, P. Cote, J. Macleod, G. Allaire, E. L. Franco and F. Coutlee, "Prevalence, Clearance, and Incidence of Anal Human Papillomavirus Infection in HIV-Infected Men: The HIPVIRG Cohort Study,” Journal of Infectious Diseases, Vol. 199, No. 7, 2009, pp. 965-973. doi:10.1086/597207 
[21] L. Gao, F. Zhou, X. Li, Y. Yang, Y. Ruan and Q. Jin, "Anal HPV Infection in HIV-Positive Men Who Have Sex with Men from China,” PLoS One, Vol. 5, No. 12, 2010, p. e15256. doi:10.1371/journal.pone.0015256

[22] C. Piketty, T. M. Darragh, I. Heard, M. Da Costa, P. Bruneval, M. D. Kazatchkine and J. M. Palefsky, "High Prevalence of Anal Squamous Intraepithelial Lesions in HIV-Positive Men Despite the Use of Highly Active Antiretroviral Therapy," Sexually Transmitted Diseases, Vol. 31, No. 2, 2004, pp. 96-99. doi:10.1097/01.OLQ.0000109515.75864.2B

[23] I. E. Salit, A. Lytwyn, J. Raboud, M. Sano, S. Chong, C. Diong, W. Chapman, J. B. Mahony and J. Tinmouth, "The Role of Cytology (Pap Tests) and Human Papillomavirus Testing in Anal Cancer Screening," AIDS, Vol. 24, No. 9, 2010, pp. 1307-1313.

[24] R. D. Cranston, S. D. Hart, J. A. Gornbein, S. L. Hirschowitz, G. Cortina and A. A. Moe, "The Prevalence, and Predictive Value, of Abnormal Anal Cytology to Diagnose Anal Dysplasia in a Population of HIV-Positive Men Who Have Sex with Men," International Journal of STD \& AIDS, Vol. 18, No. 2, 2007, pp. 77-80. doi:10.1258/095646207779949772

[25] T. C. Wright Jr., L. S. Massad, C. J. Dunton, M. Spitzer, E. J. Wilkinson and D. Solomon, "2006 Consensus Guidelines for the Management of Women with Cervical Intraepithelial Neoplasia or Adenocarcinoma in Situ," Journal of Lower Genital Tract Disease, Vol. 11, No. 4, 2007, pp. 223-239. doi:10.1097/LGT.0b013e318159408b

[26] S. E. Goldstone, C. S. Enyinna and T. W. Davis, "Detection of Oncogenic Human Papillomavirus and Other Pre- dictors of Anal High-Grade Dysplasia in Men Who Have Sex with Men with Abnormal Cytology," Diseases of the Colon \& Rectum, Vol. 52, No. 1, 2009, pp. 31-39. doi:10.1007/DCR.0b013e31819736aa

[27] P. G. Janssen, L. J. Boomsma, P. A. Buis, C. Collette, F. S. Boukes and A. N. Goudswaard, "Summary of the Practice Guideline 'Prevention and Early Diagnosis of Cervical Cancer' of the Dutch College of General Practitioners," Nederlands Tijdschrift vor Geneeskunde, Vol. 153, 2009, p. A517.

[28] C. S. Nahas, E. V. da Silva Filho, A. A. Segurado, R. F. Genevcius, R. Gerhard, E. B. Gutierrez, C. F. Marques, I. Cecconello and S. C. Nahas, "Screening Anal Dysplasia in HIV-Infected Patients: Is There an Agreement between Anal Pap Smear and High-Resolution Anoscopy-Guided Biopsy?” Diseases of the Colon \& Rectum, Vol. 52, No. 11, 2009, pp. 1854-1860. doi:10.1007/DCR.0b013e3181b98f36

[29] S. E. Goldstone, B. Winkler, L. J. Ufford, E. Alt and J. M. Palefsky, "High Prevalence of Anal Squamous Intraepithelial Lesions and Squamous-Cell Carcinoma in Men Who Have Sex with Men as Seen in a Surgical Practice," Diseases of the Colon \& Rectum, Vol. 44, No. 5, 2001, pp. 690-698. doi:10.1007/BF02234568

[30] “Guidelines European AIDS Society,” Version 5, 2009, p. 35. http://www.europeanaidsclinicalsociety.org

[31] J. M. Lam, J. S. Hoch, J. Tinmouth, M. Sano, J. Raboud and I. E. Salit, "Cost-Effectiveness of Screening for Anal Precancers in HIV-Positive Men,” AIDS, Vol. 25, No. 5, 2011, pp. 635-642. doi:10.1097/QAD.0b013e3283434594 